\title{
Lophoura (Copepoda : Sphyriidae) Parasitic on the Rattails (Pisces: Macrouridae) in the Pacific, with Note on Sphyrion lumpi from the Sea of Japan
}

\section{AUTHOR(S):}

Ho, Ju-shey; Kim, Il-Hoi

\section{CITATION:}

Ho, Ju-shey ... [et al]. Lophoura (Copepoda: Sphyriidae) Parasitic on the Rattails (Pisces: Macrouridae) in the Pacific, with Note on Sphyrion lumpi from the Sea of Japan. PUBLICATIONS OF THE SETO MARINE BIOLOGICAL LABORATORY 1989, 34(1-3): 37-54

\section{ISSUE DATE:}

1989-08-31

URL:

http://hdl.handle.net/2433/176159

RIGHT: 


\title{
Lophoura (Copepoda: Sphyriidae) Parasitic on the Rattails (Pisces: Macrouridae) in the Pacific, with Note on Sphyrion lumpi from the Sea of Japan
}

\author{
By \\ Ju-shey Ho \\ Department of Biology, California State University, Long Beach, \\ California, 90840-3702, USA \\ and
}

Il-Hoi Kim

Department of Biology, Kangreung National University, Kangreung, Kangwon-do, 210, Korea

With Text-figures $1-10$

The Sphyriidae is a family of highly transformed parasitic copepods that bore into and anchor in the host tissue with their expanded cephalothorax and/or secondarily developed holdfast organ. The part of the parasite body inserted into the host tissue is always much longer than the trunk (genito-abdomen or genital complex) that exposes out of the host body (see Fig. 3). As in many other parasitic copepods, attachment to fish host is strictly the work of the adult female sphyriids. Their cephalic appendages are extremely reduced and their thoracic appendages are absent. Nothing is known of their life cycle and larval stages. The dwarf adult male is sometimes found attached to the female. It resembles the male of the Lernaeopodidae in many respects.

Lophoura Kölliker, 1853 is the largest genus of the Sphyriidae consisting of 13 species. Of the five families of marine fishes that serve as the host of Lophoura, the rattails (Macrouridae) seem to take the heaviest burden of carrying this genus of parasites. They host six species of Lophoura, these are: L. bouvieri (Quidor, 1912), L. cardusa (Leigh-Sharpe, 1934), L. edwardsi Kölliker, 1853, L. kamoharai (Yamaguti, 1939), L. laticervix Hewitt, 1964 and L. pentaloba Ho, 1985. So far, only three species of Lophoura are known to occur in the Pacific Ocean: L. cardusa and L. kamoharai from above plus $L$. cornuta (Wilson, 1919), which parasitizes the cutthroat eels (Synaphobranchidae) off Hokkaido. In this report we shall add five species to this meager list of Lophoura occurring in the Pacific.

The material of Lophoura used in this report came from three sources. In the summer of 1984, the first author visited Prof. O. Okamura's laboratory at Kochi University in Kochi, Japan to examine his remarkable collections of the eastern

Publ. Seto Mar. Biol. Lab., 34(1/3), 37-54, 1989.

(Article 4) 
Pacific macrourids (42 species, 1,786 specimens) for copepod parasites. The specimens of Lophoura collected during that visit are the major part of the present report. Other specimens of Lophoura were obtained from the Scripps Institution of Oceanography in La Jolla, California and the South Australian Museum in Melbourne, Australia.

Recently, the second author collected a specimen of Sphyrion lumpi (Krфyer, 1845) from a deep-water scorpion fish, Sebastes flameus (Jordan et Starks), caught in the Sea of Japan. S. lumpi is the best known member of the Sphyriidae, it is hitherto recorded mostly from the North Atlantic and rarely from the South Atlantic. In this report we shall include a note on the significance of the discovery of $S$. lumpi from the Sea of Japan.

Abbreviations used in text figures. $\mathrm{A}^{\prime}$, first antenna; $\mathrm{A}^{\prime \prime}$, second antenna; AS, anal slit; CL, cephalic lobe; DL, dorsal-left trunk; DR, dorsal-right trunk; DT, dorsal trunk; GP, genital pore; MX, first maxilla; LP, left-posterior branch; LT, left trunk; PL, perianal lobe; RP, right-posterior branch; RT, right trunk; SP, spermatophore; VL, ventral-left trunk; VR, ventral-right trunk.

\section{Lophoura cardusa (Leigh-Sharpe, 1934)}

(Fig. 1)

Material examined. Four females recovered from 3 Hymenocephalus striatissimus Jordan \& Gilbert collected from Mimase, Kochi Prefecture, Japan.

Female. The cephalic region of the cephalothorax (Fig. 1A) is characteristically smooth. Its globose terminal portion that carries the modified cephalic appen. dages is clearly demarcated from the rest of the region. The basal portion of the cephalic region narrows just distal to the holdfast organ. The holdfast organ (Fig. 1A) is so irregularly branched that it is impossible to discern the basic pattern of its branching. The trunk is pear-shaped in dorsal and ventral views (Fig. 1B and D), but in lateral view (Fig. 1C), it shows a rather flat ventral surface, with the perianal lobe protruded downward at the posterior end. The posterior processes come off the base of the perianal lobe at its anterolateral surface (see the openings in Fig. $1 \mathrm{C}$ and D). Each process (Fig. 1E) consists of a stout central stalk with 25-28 rather large cylinders. The cylinders are easily detached, as shown in Fig. 1E, but their exact number can be obtained by a count including the scars on the central stalk.

Remarks. This species was described by Leigh-Sharpe (1934) based on a single specimen recovered from Hymenocephalus striatissimus taken from Makassar Strait at $450 \mathrm{~m}$ during the Siboga Expedition. It was then called "Rebelula cardusa." The cephalothorax (Fig. 1A), shape of the trunk (Fig. 1B-D), and the posterior process (Fig. 1E) of the specimens obtained from Mimase, Japan are very close to the original description.

There is no doubt that the present material is also identifiable with Yamaguti's (1939) description for "Rebelula kamoharai," which was based on the material recovered from the same host and collected from the same area (Tosa Bay). Yamaguti 


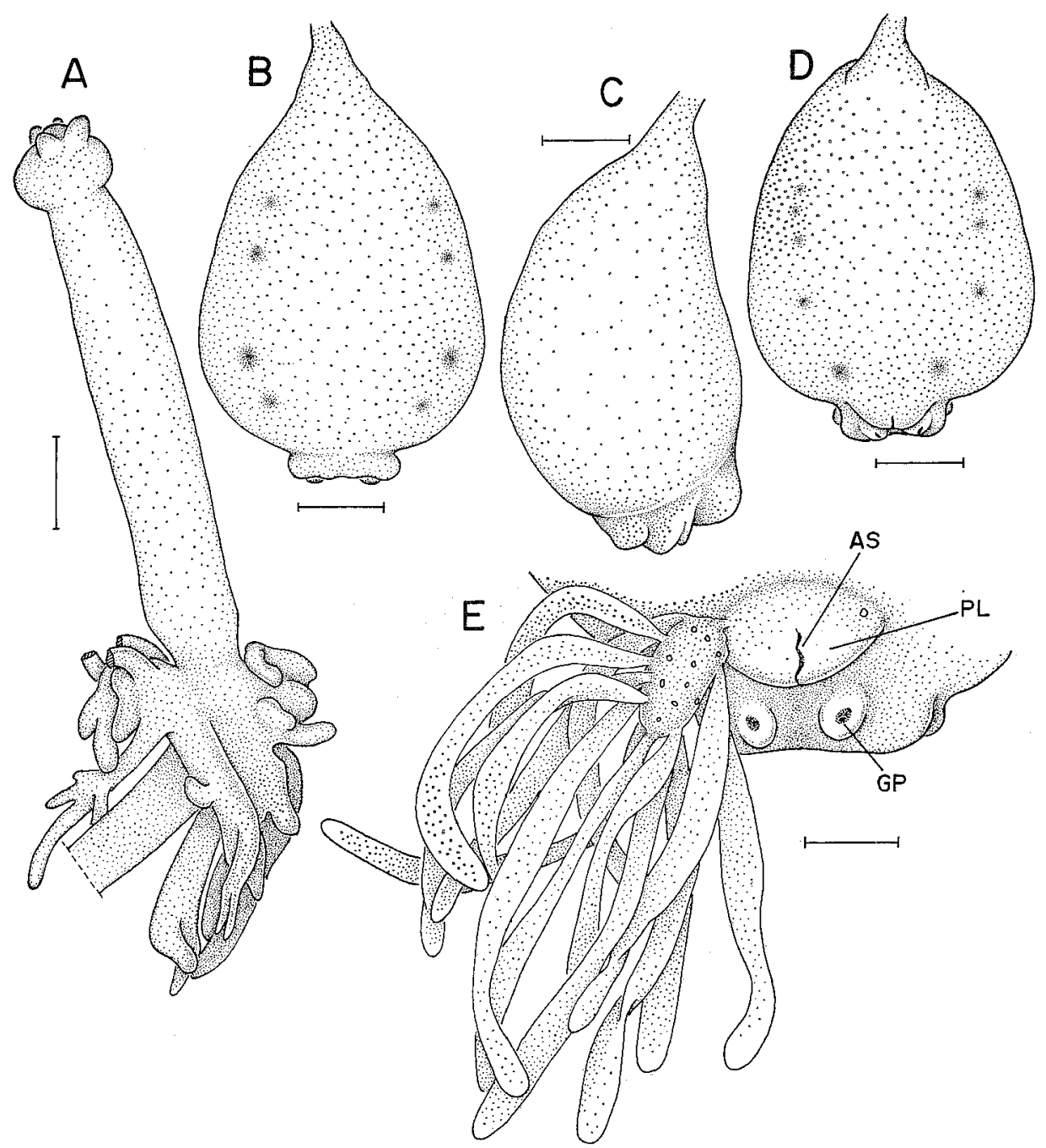

Fig. 1. Lophoura cardusa (Leigh-Spharpe, 1934), female. A. Cephalothorax and holdfast organ, dorsal; B. Trunk, dorsal; C. Same, lateral; D. Same, ventral; E. Right posterior process. Scales: $1 \mathrm{~mm}$ in $\mathrm{A}, \mathrm{E} ; 2 \mathrm{~mm}$ in $\mathrm{B}, \mathrm{C}, \mathrm{D}$.

called it a new species chiefly because his specimens had higher number $(20-26)$ of cylinders on the posterior process than L. cardusa. However, the single specimen that Leigh-Sharpe (1934) examined was like the one illustrated here in Fig. 1E, with some of its cylinders missing from the central stalk of the posterior process (see Leigh-Sharpe, 1934, Fig. 37). Therefore, taking this misinterpretation into consideration, we propose to relegate Lophoura kamoharai (Yamaguti, 1939) to a junior synonym of L. cardusa (Leigh-Sharpe, 1934). 


\section{Lophoura pentaloba Ho, 1985}

(Fig. 2)

Material examined. Two females recovered from two Coryphaenoides filifer (Gilbert) (SIO 87-80) collected off southern California and deposited in Scripps Institution of Oceanography, La Jolla, Califormia.

Female. The cephalic region of the cephalothorax (Fig. 2A) is slightly wrinkled. Its globose terminal portion is tipped with a bilobate protrusion (=modified first antennae?). The neck region of the cephalothorax (posterior to the holdfast organ) is slender and heavily sclerotized. The holdfast organ is essentially made up of 5 trunks (DT, DR, VR, DL, and VL in Fig. 2B and C), with each trunk bearing vari-
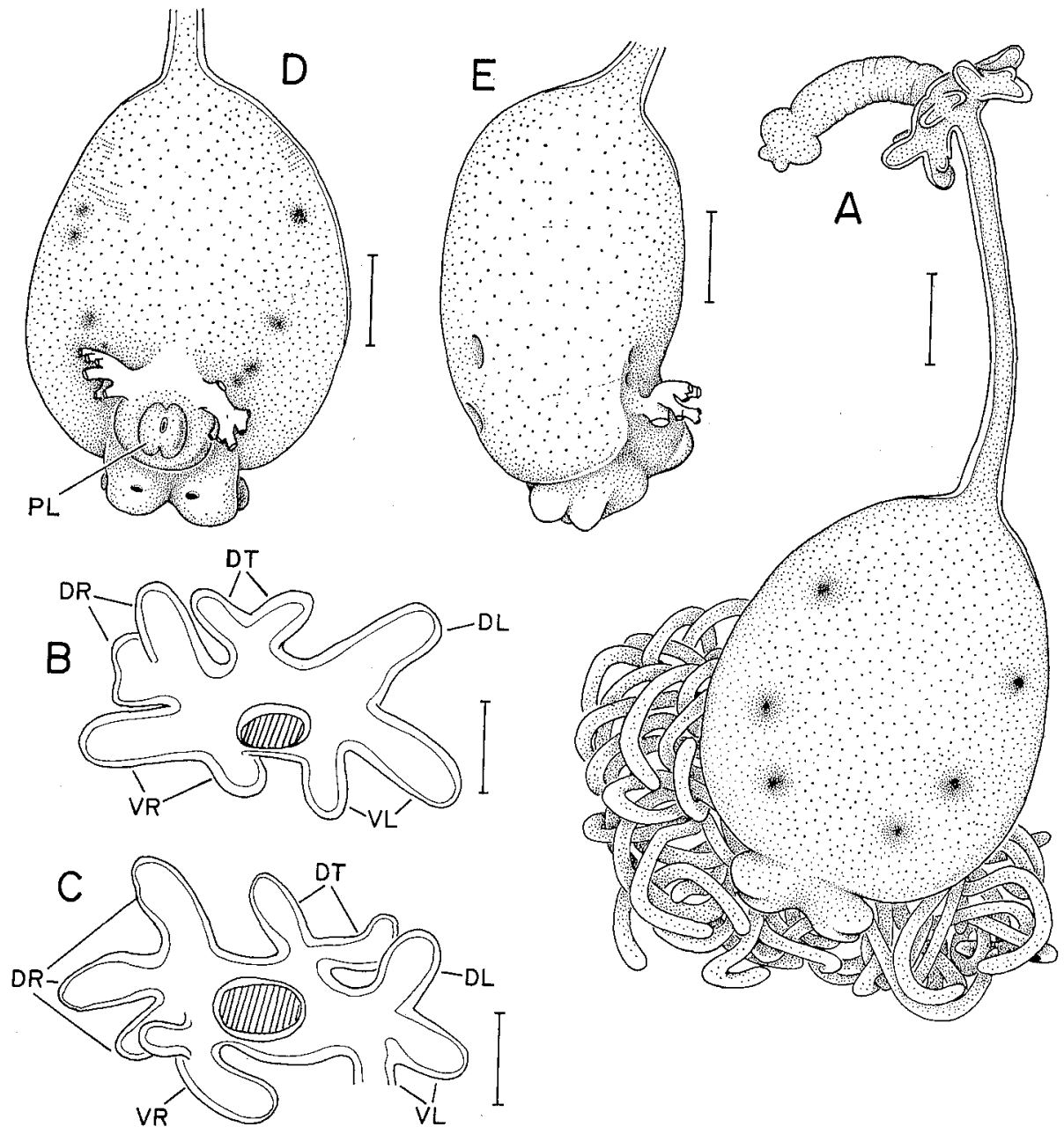

Fig. 2. Lophoura pentaloba Ho, 1985, female. A. Habitus, dorsal; B. Holdfast organ, anterior; C. Holdfast organ, anterior; D. Trunk, ventral; E. Same, lateral. Scales: $4 \mathrm{~mm}$ in A, D, E; $2 \mathrm{~mm}$ in $\mathrm{B}, \mathrm{C}$. 
ous number of branches. The trunk of the body (Fig. 2A, D and E) is sub-elliptical, with two rows of three depressions on dorsal surface. The attachment area of egg sacs is sharply set off from the posterior surface of the trunk and bears a prominent posterior indentation (see Fig. 2A). The perianal lobe is small and subterminally located (see Fig. 2E). The posterior process is very different from the one described above for $L$. cardusa, it consists of an extremely short central stalk sending off repeatedly branching stems (see Fig. 2D and E), from which numerous slender and curved cylinders arise (see Fig. 2A). Both specimens seem to have lost some cylinders.

Remarks. This report extends the range of $L$. pentaloba from the western North Atlantic to the eastern North Pacific. In the Atlantic it is also found on the macrourids (Ho, 1985).

The illustration in Fig. 2A is drawn from the larger specimen (measuring 48.7 $\mathrm{mm}$ in total length) of the two collected. The branches on its holdfast organ (Fig. 2B) is slightly different from those found on the smaller specimen (Fig. 2C). The same variation in the holdfast branches was also noticed by Ho (1985) in the Atlantic material.

It is extremely difficult to determine the exact number of cylinders on the posterior process of this species, because they are easily detached and do not leave corresponding number of scars, due to the pattern of repeatedly branching growth. Ho (1985) described: "each posterior process with 15+ slender cylinders" for the North Atlantic specimen, but based on our observation there are at least 40 cylinders on each posterior process.

\section{Lophoura ventricula, new species}

(Figs 3-5)

Material examined. Three females removed from 3 Coryphaenoides nasutus Günther collected from Tosa Bay, Japan. One male was found attached to posterior process of a female which was designated holotype. Holotype together with one paratype were deposited in the United States National Muscum of Natural History, Washington, D.C.; other paratype and allotype were dissected and kept in the senior author's collection.

Female. The body (Fig. 4A) is relatively short for a sphyriid. The cephalic region of the cephalothorax is rather well demarcated (see Fig. 4B-C). Two specimens (including the holotype) have their processes on the holdfast organ turned forward, reminding one of a cluster of tentacles surrounding the manubrium in a

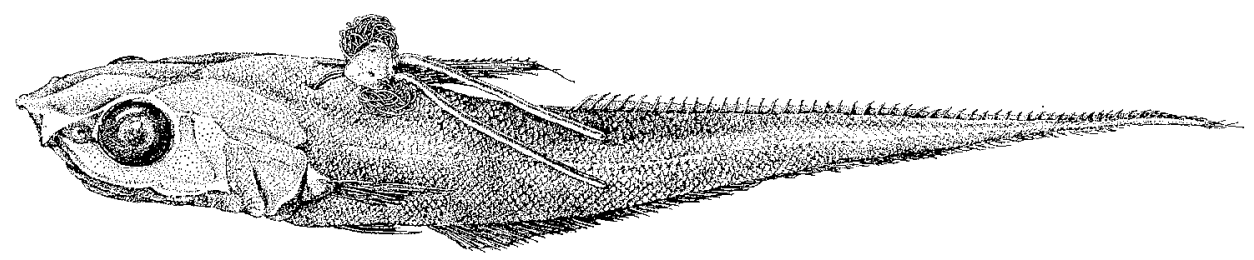

Fig. 3. An ovigerous female of Lophoura ventricula, new species attaching to Coryphaenoides nasutus Günther collected from Tosa Bay, Japan. 

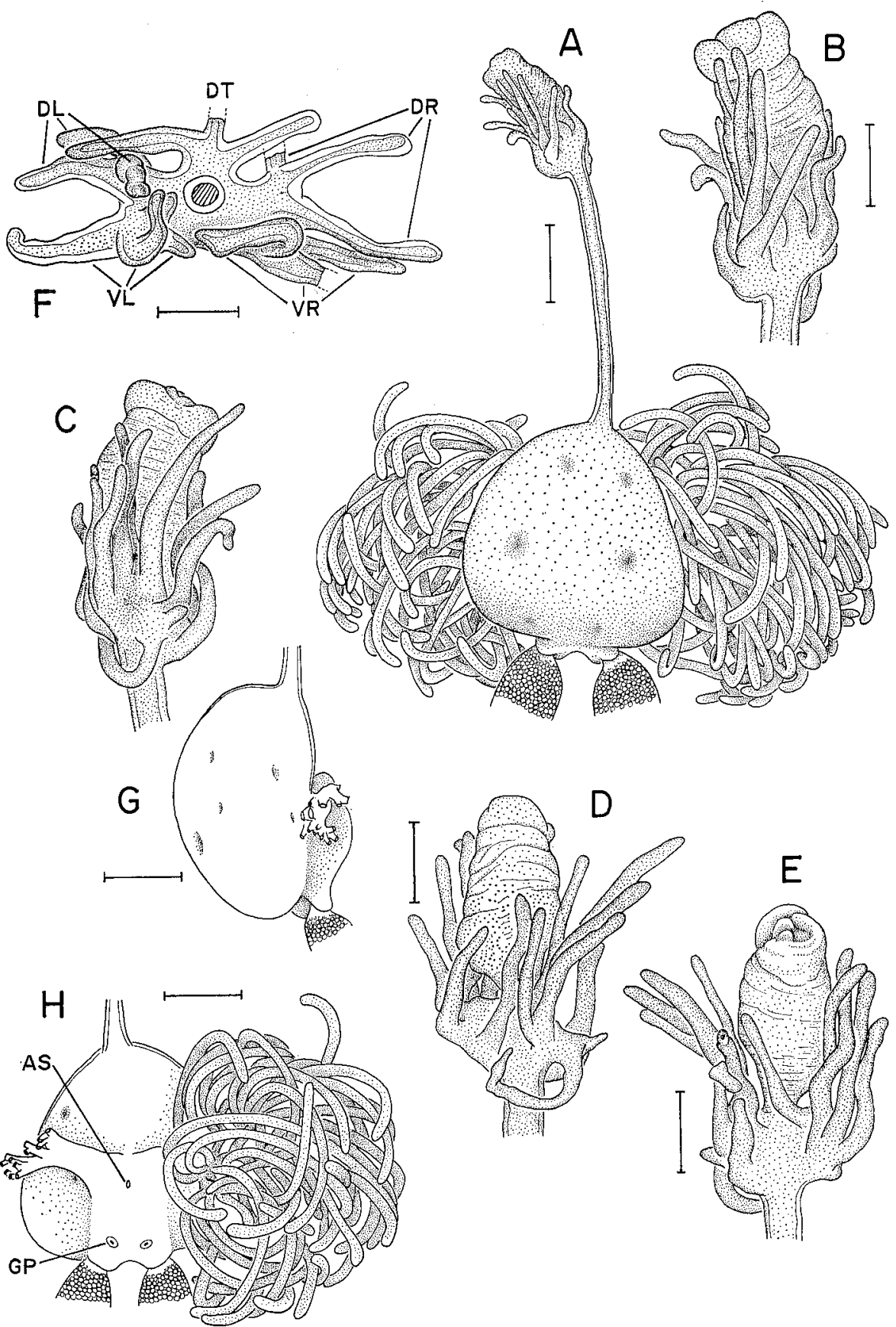

Fig. 4. Lophoura ventricula, new species, female. A. Habitus of holotype, dorsal; B. Cephalothorax and holdfast organ of holotype, dorsal; C. Same, ventral; D. Same, right; E. Same, left; F. Holdfast organ of paratype, posterior; G. Trunk of holotype, lateral; H. Same ventral. Scales: $4 \mathrm{~mm}$ in $\mathrm{A}, \mathrm{G}, \mathrm{H} ; 2 \mathrm{~mm}$ in $\mathrm{B}, \mathrm{C}, \mathrm{D}, \mathrm{E}, \mathrm{F}$. 


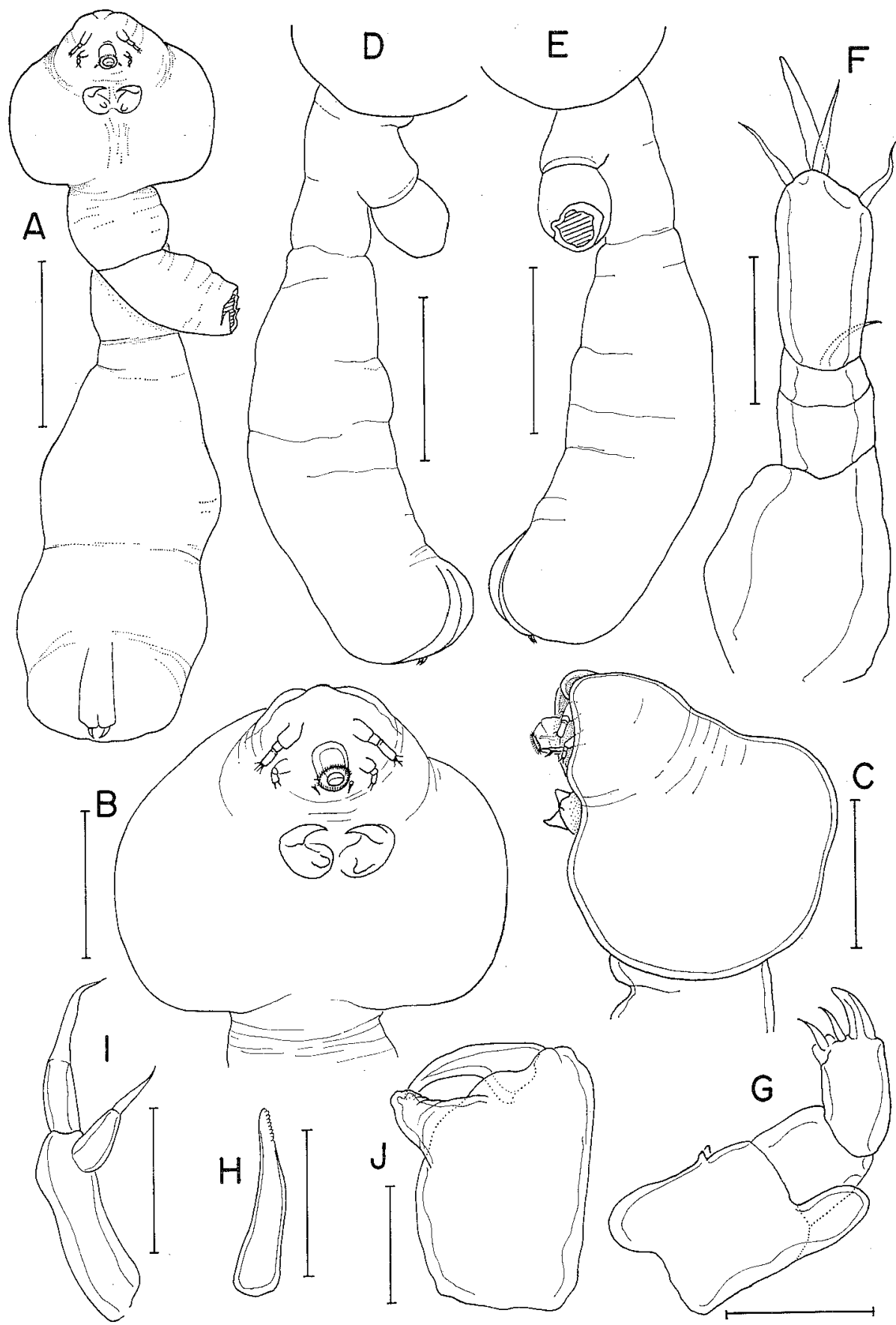

Fig. 5. Lophoura ventricula, new species, male (allotype). A. Habitus, ventral; B. Head, ventral; C. Same, lateral; D. Neck and trunk, right; E. Same, left; F. First antenna; G. Second antenna; H. Mandible; I. First maxilla; J. Second maxilla. Scales: $1 \mathrm{~mm}$ in $\mathrm{A}, \mathrm{D}, \mathrm{E} ; 0.5 \mathrm{~mm}$ in $\mathrm{B}, \mathrm{C} ; 0.05 \mathrm{~mm}$ in $\mathrm{F}, \mathrm{G}, \mathrm{H}, \mathrm{I} ; 0.1 \mathrm{~mm}$ in J. 
hydroid (see Fig. 4B-E). However, the third specimen has its holdfast processes horizontally extended as in most species of Lophoura. Based on this paratypic specimen, the holdfast organ seems to be made up of five trunks (DT, DR, VR, DL and $\mathrm{VL}$ in Fig. 4F), with each trunk bearing three or more long processes. The slender, smooth neck region posterior to the holdfast is only about twice the length of the swollen and wrinkled cephalothorax (see Fig. 4A).

The trunk (genito-abdomen) is about as wide $(11.6 \mathrm{~mm})$ as long $(12.2 \mathrm{~mm})$. It has convex dorsal surface and flat ventral surface (Fig. 4G). The attachment area of egg sacs and the perianal lobe are swollen and fused into a large elevated area (see Fig. 4G), and located in the central, posterior half of the trunk ventral surface (Fig. 4H). Consequently, the stalks of the posterior processes are transposed to the midventral surface of the trunk. There are $80+$ long and curved cylinders on each posterior process, they arise from the distal end of the central stalk (see Fig. $4 \mathrm{G}-\mathrm{H}$ ). Anal pore and genital pores are far apart (Fig. 4H). The egg sac can be several times longer than the trunk (see Fig. 3), it contains many rows of small eggs. The total length of the holotype is $31.7 \mathrm{~mm}$.

Male. The body (Fig. 5A), measuring $4.09 \mathrm{~mm}$ long and $1.14 \mathrm{~mm}$ wide, is clearly divided into three parts: a swollen head, a cylindrical neck, and an inflated trunk. The head (Fig. 5B-C) carries all cephalic appendages except the maxillipeds, which occur in the neck region. The neck region is the shortest of the three parts, with the fused stem of maxillipeds arising from its midventral surface (Fig. 5D-E). The trunk carries a pair of reduced caudal rami on its truncated posterior surface (Fig. 5E).

The first antenna (Fig. 5F) is 3-segmented; armature on these segments is: 0, 1, and $3+1$ aesthete. The second antenna (Fig. 5G) is 3-segmented; the second segment is unarmed, but first segment bears an outer, blunt protuberance on the distal corner and 2 denticles on the inner surface, and the distal segment is tipped with 1 spine and 2 setae. The mandible (Fig. $5 \mathrm{H}$ ) is extremely small, of caligid form and bearing 7 or 8 teeth; there is no secondary tooth as in some lernaeopodids. The first maxilla (Fig. 5I) is biramous, each ramus carries a distal seta. The second maxilla (Fig. 5J) is 2-segmented; the robust corpus carries on its medial surface a large conical process and the second segment is in a form of terminal claw. The maxillipeds are born at the tip of a large ventral process coming off the center of the neck region (Fig. 5A, broken off in this specimen). Legs are absent.

Mode of attachment. The parasite bores into the myotome near the base of the dorsal fin (Fig. 3); two parasites were found on the left side of the host and the third, on the right side. The cephalothorax was either lodged in the muscle or free in the coelom.

Etymology. The specific name ventricula (=the belly in Latin) refers to the large ventral elevation (perianal lobe) that supports the profusely branched posterior processes (see Fig. 4G-H). 
Remarks. The most outstanding characteristic of this new species is the structure of the cylinders on the posterior process, which are long, curved, and numerous. The clusters of these cylinders are larger than the trunk; in other words, they are not concealed by the trunk in dorsal view of the parasite (see Fig. $4 \mathrm{~A}$ and $\mathrm{H}$ ). The structure of the posterior process is very much like the one seen in L. pentaloba, but its location on the trunk is quite different (cf. Fig. 2A and Fig. 4A).

The male of Sphyriidae is rarely found. In the genus Lophoura, it has been reported for only three species: L. bouvieri (Quidor), L. cornuta (Wilson), and L. caparti (Nunes-Ruivo, 1962). The first two species were reported by Wilson (1919) and the third one, by Nunes-Ruivo (1962) in her original description of the species. The gross morphology of those three males and the one reported above are almost identical, without noticeable differences. Since the cephalic appendages, including the mouth parts are not well-known in the other three species, it is impossible to make a comparison of their appendages.

\section{Lophoura tetraloba, new species}

(Figs 6-7)

Material examined. Eleven females removed from 8 Nezumia sp. collected from South China Sea and 3 females (one designated holotype and the other two paratypes) removed from 3 Nezumia condylura Jordan \& Gilbert collected from Tosa Bay, Japan. Holotype, one paratype and two specimens from South China Sea were deposited in the United States National Museum of Natural History, Washington, D.G. The dissected paratype and the remaining material kept in the senior author's collection.

Female. The body (Fig. 6A) consists of a slender, cylindrical anterior part, including the cephalothorax and the holdfast organ, and a round, flattened posterior part (trunk) carrying a pair of posterior processes and egg sacs. The cephalic region of the cephalothorax (Fig. 6B-C) is sharply set off from the remainder, its anterior end is slightly bilobate and its posteroventral surface carries a pair of relatively large lobes (CL in Fig. 6B-C). The holdfast organ is primarily made up of four trunks (DL, DR, VL and VR in Fig. 6B), which may or may not bear tubercles. The number and size of those tubercles on the holdfast processes also vary from one to the other on the same specimen. The neck region posterior to the holdfast organ is heavily sclerotized, it attaches to the lower portion of the anterior surface of the trunk and is sharply set off from it (see Fig. 7B).

The trunk (genito-abdomen) has two longitudinal rows of depressions on both dorsal and ventral surfaces lateral to the central ridge (Fig. 7B). The attachment area of egg sacs is sharply demarcated from the posterior surface of the trunk and bears a concave posterior margin (Fig. 6A). Each egg sac attaches to the slit (oviducal opening) located on the posterolateral surface of this attachment area expansion. Ventral to the attachment area of egg sacs there is an elliptic perianal lobe (see Fig. 6D) with a longitudinal slit in the center (AS in Fig. 7A). Just posterior to this perianal lobe there is a pair of genital tubercles bearing a genital opening 


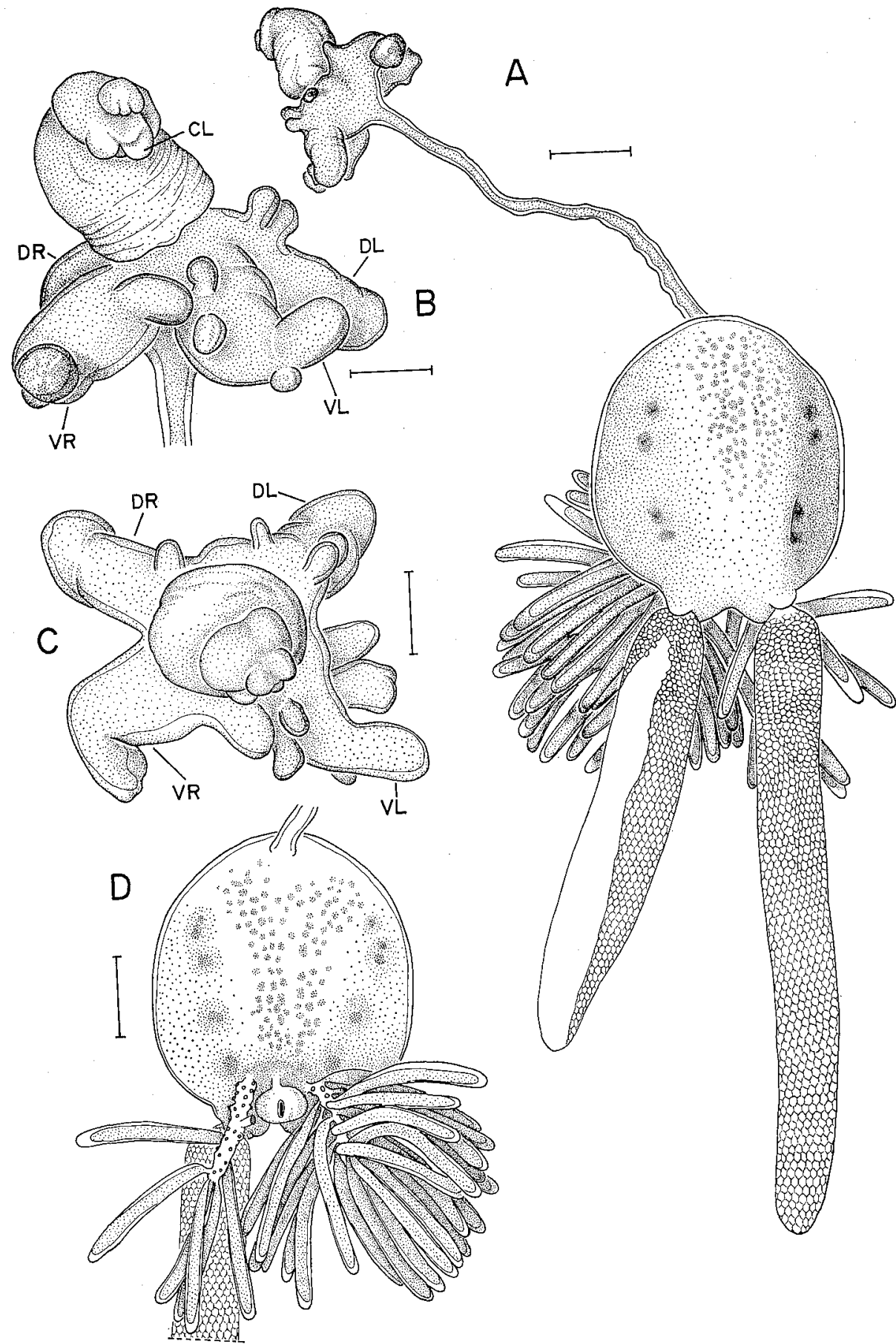

Fig. 6. Lophoura tetraloba, new species, female (holotype). A. Habitus, dorsal; B. Cephalothorax and holdfast organ, ventral; C. Same, anterior; D. Trunk, ventral. Scales: $2 \mathrm{~mm}$ in $\mathrm{A}, \mathrm{D} ; 1 \mathrm{~mm}$ in $\mathrm{B}, \mathrm{G}$. 


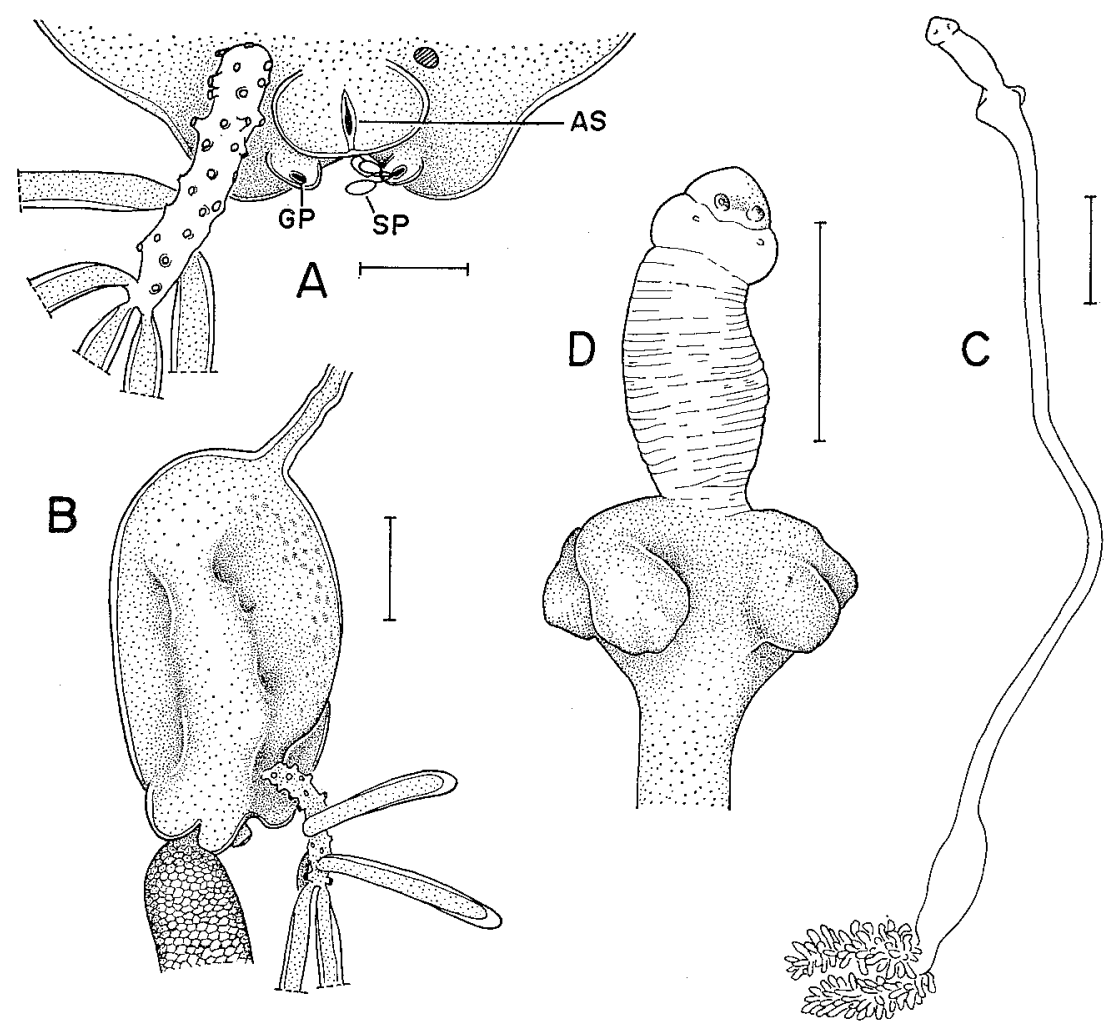

Fig. 7. Lophoura tetraloba, new species, female. A. Posterior part of trunk of holotype, ventral; B. Trunk of holotype, lateral; C. Juvenile female, lateral; D. Cephalothorax and holdfast organ of juvenile female, ventral. Scales: $1 \mathrm{~mm}$ in $\mathrm{A}, \mathrm{D} ; 2 \mathrm{~mm}$ in $\mathrm{B}, \mathrm{C}$.

(GP in Fig. 7A) at the tip. It may carry spermatophores as shown in Fig. 7A. The posterior process consists of a central stalk bearing $30+$ slender cylinders, which are attached to the stalk with a short, narrow neck (Figs. 6D, 7A). The egg sac is large, containing many rows of eggs (Fig. 6A), it may reach more than twice the length of the body. The total length of the holotype is $21.5 \mathrm{~mm}$.

Juvenile female. As shown in Fig. 7G, a young female, measuring $18.8 \mathrm{~mm}$ (excluding posterior processes), with reduced trunk and small posterior processes, was found from the Nezumia sp. collected from the South China Sea. It is interesting to point out that its holdfast organ is made up of four lobes (Fig. 7D), representing the four processes found in the fully grown, ovigerous female. Apparently, the size of the cylinders and stalk in the posterior process also grows with the maturation of the parasite.

Mode of attachment. In all instances, the parasite has its cephalothorax and holdfast organ inserted inside the host's liver. The parasite's insertion starts at the base of the host's dorsal fin, penetrates through myotomes, enters the body cavity between the pleural ribs, and then comes in contact with the liver. The penetration can be 
so severe that the tip of the cephalothorax comes out of the host's liver on the opposite side of the organ. Curiously, penetration from the left side of the host body seems to be preferred over the right side, but, when there are two parasites on the host, one always penetrates from the right side.

Etymology. The specific name tetraloba (=four lobes in Greek) refers to the basic pattern of four processes in the holdfast organ.

Remarks. This is the only Lophoura known to penetrate into the liver of its host. It is also characteristic in having the holdfast organ consisting of four trunks. Two other species of Lophoura are also known to have four-part holdfast organ. L. tetraphylla, which was found on the macrourids in the Atlantic, differs from L. tetraloba in having its four parts of the holdfast organ tremendously enlarged like inflated baloons (Ho, 1985). Also, its cephalothorax is not thicker than the neck as in $L$. tetraloba. The other species is $L$. cornuta. This species is not a parasite of macrourids, it differs from L. tetraloba in having each of the four trunks of the holdfast organ bearing profusely branched, long, slender, and twisted processes (Wilson, 1919). Besides, the neck of $L$. cornuta is approximately as long as the trunk, but in L. tetraloba it is distinctly longer than the trunk.

\section{Lophoura bipartita, new species}

(Fig. 8)

Material examined. Three females removed from 3 Coryphaenoides subserrulatus deposited in South Australian Museum. The hosts were collected at $39^{\circ} 16^{\prime} \mathrm{S} 148^{\circ} 44^{\prime} \mathrm{E}$ ( $45 \mathrm{~km}$ northeast of East Sister Island, Australia) from $660 \mathrm{~m}$ deep water, on 13 October, 1984. Holotype and two paratypes deposited in South Australian Museum.

Female. The body (Fig. 8A) has a long neck and cephalothorax. The latter is characteristic in having two parts: a soft, wrinkled anterior part and a heavily sclerotized, smooth posterior part. The cephalic region of the cephalothorax is well demarcated from the remainder and tipped with two rounded lobes (Fig. 8B). The holdfast organ is fairly large (Fig. 8A, C), consisting of two major horizontal trunks. Each trunk (RT or LT in Fig. 8A, G) bears a posteriorly directed process ( $\mathrm{RP}$ or LP in Fig. 8A, G) with either 2 or 3 branches. Each of the laterally projected trunk proper (RT or LT in Fig. 8A, G) bears 4 branches. The neck $(12.7 \mathrm{~mm}$ ) is shorter than the cephalothorax (14.7 mm) (see Fig. 8A).

The trunk (genito-abdomen) has two rows of three prominent depressions on the dorsal surface (Fig. 8A) and turns downward in the posterior half (Fig. 8E). The attachment area of egg sacs has a deep posterior notch (Fig. 8A, D) and swollen ventrally. There are about 40 long and curved cylinders on the posterior process, they arise from the end of an extremely short stalk. The total length of the holotype is $39.5 \mathrm{~mm}$. 


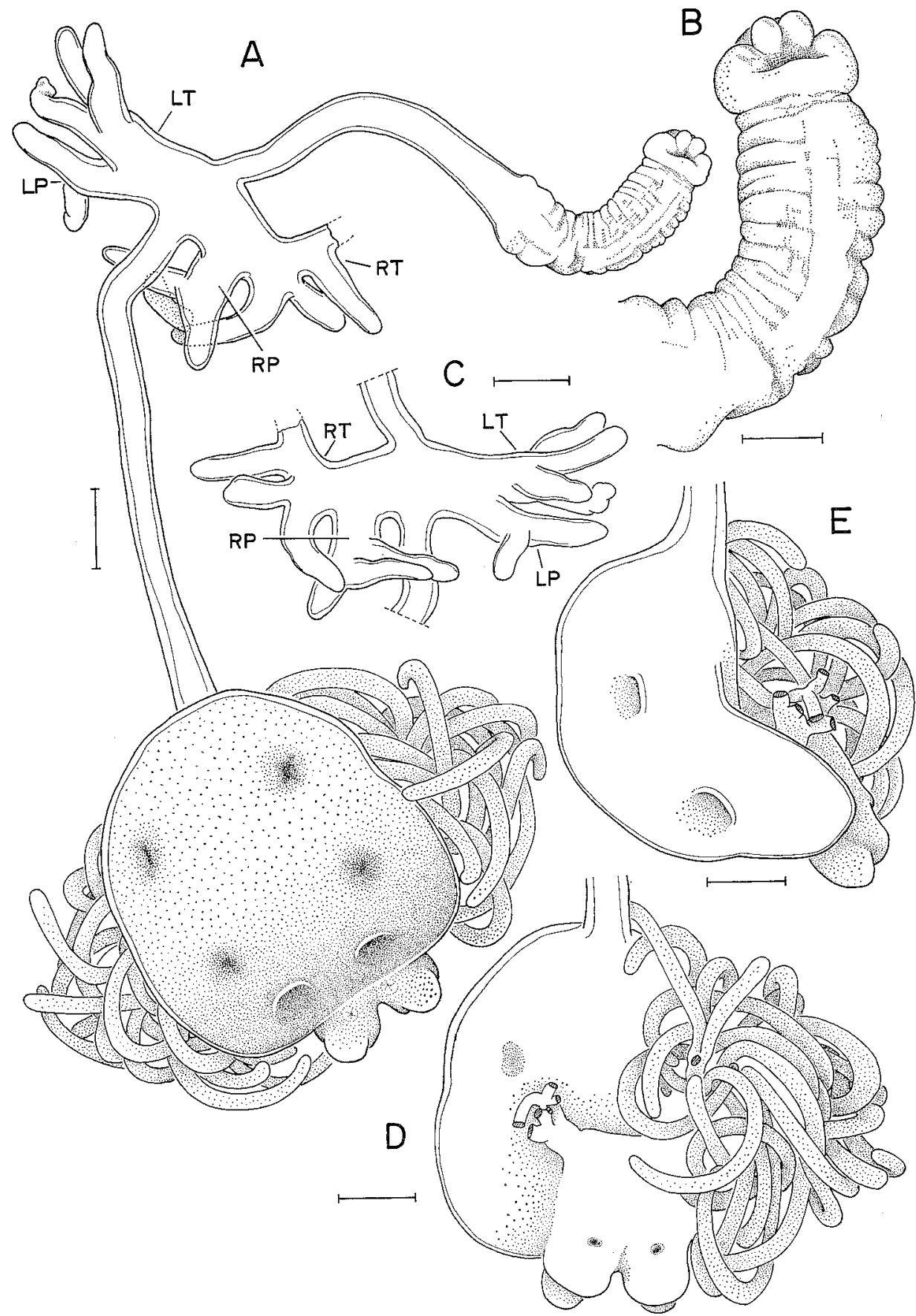

Fig. 8. Lophoura bipartita, new species, female (holotype). A. Habitus, dorsal; B. Cephalothorax, dorsal; C. Holdfast organ, ventral; D. Trunk, ventral; E. Same, lateral. Scales: $2 \mathrm{~mm}$ in $\mathrm{A}, \mathrm{C}, \mathrm{D}, \mathrm{E} ; 1 \mathrm{~mm}$ in $\mathrm{B}$. 
Remarks. The most outstanding feature of the present species is having a cephalothorax longer than the neck. This feature is shared with only one species of its congener, L. elongata. However, the structure of the posterior process is very different between these two species. In L. elongata it is almost like the one present in L. tetraloba (see Fig. 6A), i.e. the cylinders are relatively short and straight and almost entirley exposed (not concealed in dorsal view of the parasite). Besides, $L$. elongata is a parasite of the Synaphobranchidae, not the Macrouridae (Kensley \& Grindley, 1973).

The cephalothorax of $L$. bipartita bears another outstanding feature, i.e. its division into an anterior soft, wrinkled portion and a posterior rigid, smooth portion. This peculiar feature of the cephalothorax is again shared with only one other congener, L. tripartita. However, as in the case of $L$. elongata, the new species can be easily separated from $L$. tripartita by the structure of the posterior process. The host of L. tripartita is an unusual one for the Lophoura, it is Calamus bajanado (Bloch \& Schneider) [misspelled in Wilson's (1935) original description as "bajonado"), a species

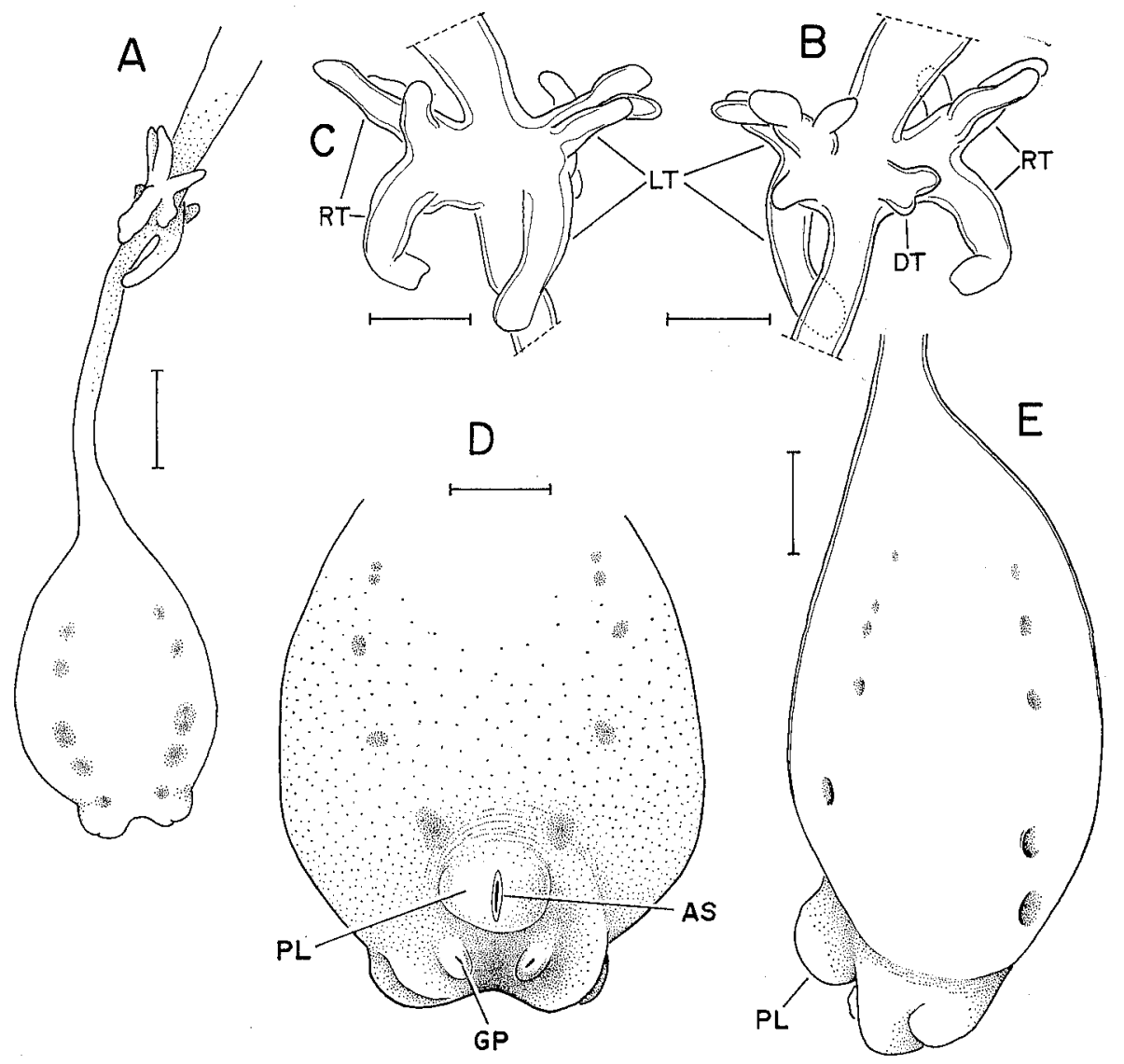

Fig. 9. Lophoura sp., female. A. Habitus, dorsal; B. Holdfast organ, dorsal; C. Same, ventral; D. Trunk, ventral; E. Same, lateral. Scales: $2 \mathrm{~mm}$ in $\mathrm{A} ; 1 \mathrm{~mm}$ in $\mathrm{B}, \mathrm{C}, \mathrm{D}$, E. 
of the Sapridae from the Gulf of Mexico.

\section{Lophoura sp.}

(Fig. 9)

Material examined. One incomplete female recovered from a Ventrifossa japonica (Matsubara) collected off Okinawa.

Female. The cephalothorax (Fig. 9A) is soft, smooth, and larger than the neck. The anterior portion of the cephalothorax is broken. The holdfast organ (Fig. 9BC) consists of 3 main trunks; the dorsal trunk (DT in Fig. 9B) is the smallest and slightly bilobed; both left and right trunks bear larger branches, with 4 branches on the right trunk and 6 branches on the left trunk.

The trunk (genito-abdomen) is pyriform, bearing two rows of 5 depressions on both dorsal (Fig. 9A) and ventral (Fig. 9D) surfaces. The attachment area of egg sacs has emarginated posterior surface (Fig. 9A, D). The perianal lobe (PL in Fig. 9D-E) is large and elevated, bearing a long anal slits (AS in Fig. 9D) at its summit. A pair of genital tubercles (GT in Fig. 9D) sit behind the perianal lobe on the ventral surface. The posterior processes were broken.

Remarks. This is an imcomplete specimen, and probably representing a young, nonovigerous specimen (less than $10 \mathrm{~mm}$ in total length). Although the structure of the holdfast organ is rather unique for Lophoura in having three main trunks, without knowledge of its posterior processes (one of the most important taxonomic features) we feel unjustified to give it a name. However, we are confident that it represent a new species.

\section{Note on Sphyrion lumpi (Kroyer, 1845)}

On July 10, 1988 a single specimen of $S$. lumpi was recovered from a deep-water scorpion fish, Sebastes flameus (Jordan \& Starks), sold in a fish market in Kangreung, Korea. It was caught off the east coast of Korea in the Sea of Japan. The body (Fig. 10A) of this oriental specimen, measuring $57.3 \mathrm{~mm}$ in total length, resembles closely those found in the North Atlantic (Templeman \& Squires, 1960; Kabata, 1979). The first antenna ( $A^{\prime}$ in Fig. $10 B$ and $C$ ), second antenna ( $A^{\prime \prime}$ in Fig. 10B and $\mathrm{D}$ ), and second maxilla ( $\mathrm{MX}$ in Fig. $10 \mathrm{~B}$ and $\mathrm{E}$ ) are also close to those described by Kabata (1979) for the European population. We were unable to find the first maxilla and the maxilliped from our specimen, although they were described by Kabata from the European population. The mandible of $S$. lumpi remains unknown. It has never been described in spite of frequent rediscovery of the parasite from the North Atlantic. However, based on Jones \& Matthews' (1968) study on the early development, the mandible in $S$. lumpi perhaps never develops after the nauplius stage, for the metanauplius (first copepodid?) described by them does not seem to have the mandible. 

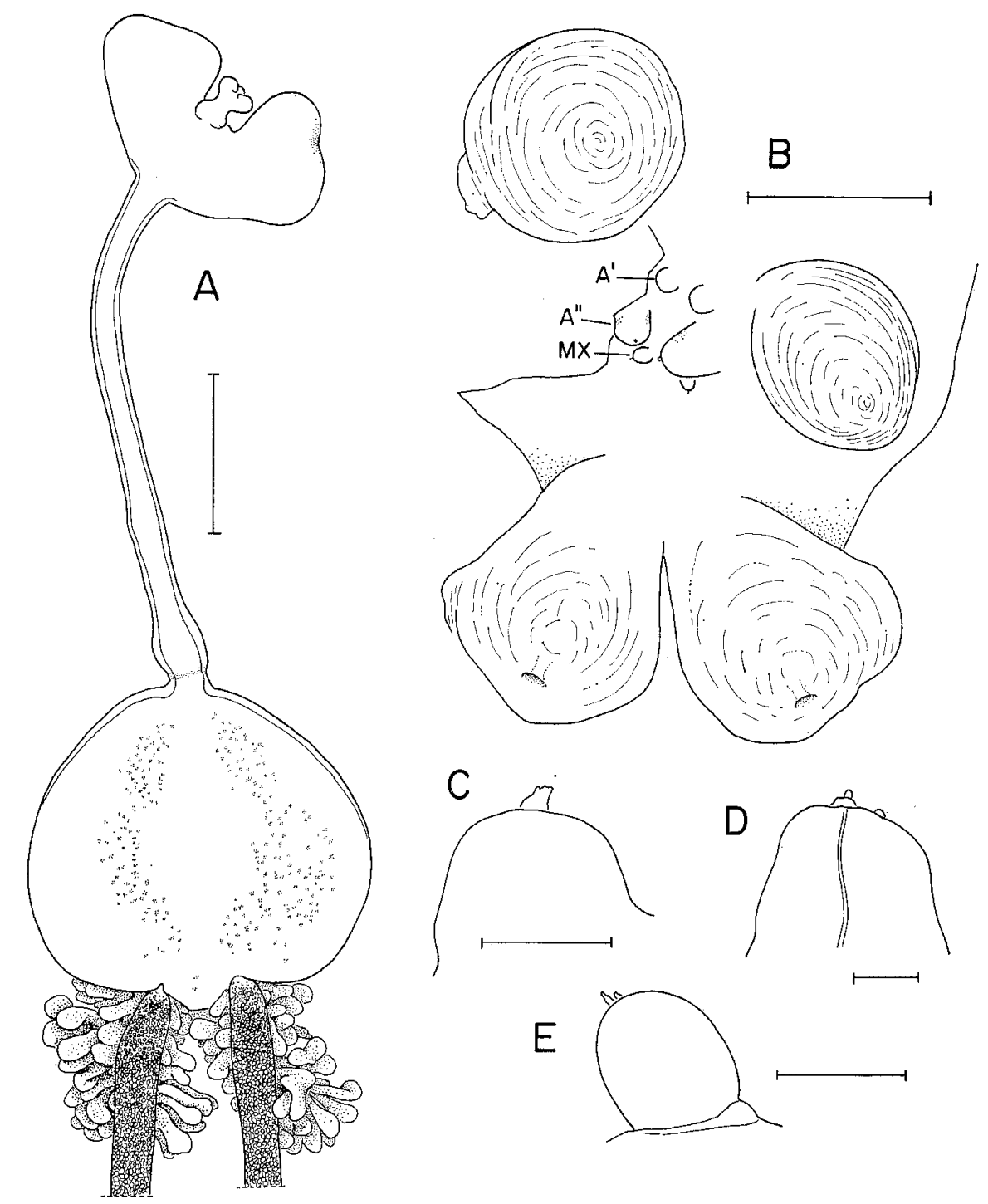

Fig. 10. Sphyrion lumpi (Krфyer), female. A. Habitus, ventral; B. Antennal and oral region, ventrolateral; C. First antenna, lateral; D. Second antenna, lateral; E. First maxilla, lateral. Scales: $10 \mathrm{~mm}$ in $\mathrm{A} ; 1 \mathrm{~mm}$ in $\mathrm{B} ; 0.1 \mathrm{~mm}$ in $\mathrm{C}, \mathrm{D}, \mathrm{E}$.

$S$. lumpi is one of the very few species of parasitic copepods that have gained much popularity among the biologists. For instance, The Society of Parasitologists of the German Democratic Republic is planning to sponsor a 3-day workshop on Sphyrion lumpi, which is to take place in October, 1989 in Güstrow, East Germany (Prof. Dr. L.W. Reimer, personal communication). Also, a preliminary survey of literature revealed that $S$. lumpi has been cited or reported nearly 70 times ever since its discovery in the middle of the 19th century. Aside from the works of Barnard 
(1955) and Capart (1959) reporting the occurrence of $S$. lumpi in the South Atlantic (off South Africa and Angola), all remaining reports of this parasite recorded the North Atlantic as its habitat. Therefore, our find of $S$. lumpi from the Sea of Japan is rather significant. It makes one wonder how the parasite dispersed so far away from its "home water." Nevertheless, this is not an unique case. Ho (1975) has discovered that chondracanthid copepods parasitic on deep-sea fishes of the Macrouridae hitherto known only from the North Atlantic were also present on some deepsea macrourids from the Galapagos Islands and New Zealand. It may seem that copepod parasites of deep-water fish tend to have wide distribution.

S. lumpi is fairly common in the North Atlantic. Although twelve species of fishes in four orders (Perciformes, Pleuronectiformes, Gadiformes, and Scorpaeniformes) were recorded to host S. lumpi, Kabata (1979) considered Sebastes as the chief host of this parasite. He also noted that the hosts of $S$. lumpi in the North Atlantic are generally deep-water inhabitants. This notion of $S$. lumpi's preference for deep-water fish, particularly the fishes of the Sebastes, was borne out by Schram's (1980) study on the copepod parasites of the polar cod, Boreogadus saida (Lepechin) from Spitsbergen. Of the 3,011 specimens examined, only two were found to harbor S. lumpi.

Although the dispersal of copepod parasites in the deep-water is still a matter of speculation, this recording of $S$. lumpi in the Sea of Japan can not be dismissed as a doubtful record, particularly when it is demonstrated that $S$. lumpi has the propencity of occurring on deep-water fish of the genus Sebastes.

\section{Acknowledgements}

We wish to thank Prof. O. Okamura, Kochi University, for providing the first author a rare opportunity of examining his excellent collections of macrourids for copepod parasites; Dr. Richard $\mathrm{H}$. Rossenblatt, Scripps Institution of Oceanography, for allowing us to remove the specimens of Lophoura pentaloba from the two Coryphaenoides flifer in the SIO collection; and Dr. Masahiro Dojiri for allowing us to study the specimens of Lophoura bipartita, which were on loan to him from South Australian Museum. This work was completed while the second author was on a Fellowship from the Korea Science and Engineering Foundation (KOSEF) to visit the Institute of Parasitology, California State University, Long Beach, California.

\section{References}

Barnard, K.H. 1955. South African parasitic Copepoda. Ann. S. African Mus., 41: 223-312. Capart, A. 1959. Copepodes parasites. In: Results Expédition océanographique Belge dans les Eaux Côtieres Africaines de l'Atlantique sud (1948-1949). Inst. Roy. Sci. nat Belg., 3: 57-126.

Ho, J.S. 1975. Cyclopoid copepods of the family Chondracanthidae parasitic on New Zealand marine fishes. Publ. Seto Mar. Biol. Lab., 22: 303-319.

1985. Copepod parasites of deep-sea benthic fishes from the western North Atlantic. Parasitol., 90: 485-497.

Jones, D.H. \& J.B.L. Matthews. 1968. On the development of Sphyrion lumpi (Krфyer). Crustaceana, Suppl., 1: 177-185.

Kensley, B. \& J.R. Grindley, 1973. South African parasitic Copepoda. Ann. S. African Mus., $62(3): 69-130$. 
Kabata, Z. 1979. Parasitic Copepoda of British fishes. Pp. 1-468. The Ray Society, London.

Leigh-Spharpe, W.H. 1934. The Copepoda of the Siboga Expedition, 2. Commensal and parasitic Copepoda. Siboga Exped. Monogr., 29B: 1-43.

Nunes-Ruivo, L. 1962. Copépodes parasites de poissons des côtes d'Angola. (2 eme Serie). Mem. Junta Invest. Ultram., 2e Ser., 33: 67-86.

Schram, T.A. 1980. The parasitic copepods Clavella adunca (Str $\phi \mathrm{m}$ ), Haemobaphes cyclopterina (Fabricius), and Sphyrion lumpi (Kr $\phi$ yer) on polar cod, Boreogadus saida (Lepechin) from Spitsbergen. Sarsia, 65: 273-286.

Wilson, G.B. 1919. North American parasitic copepods belonging to the new family Sphyriidae. Proc. U.S. nat. Mus., 55: 549-604.

1935. Parasitic copepods from the Dry Tortugas. Pap. Tortugas Lab., 29: 329-347.

Yamaguti, S. 1939. Parasitic copepods from fishes of Japan, 6. Lernaeopodoida I. Vol. jub. Prof. Sadao Yoshida, 2: 529-578. 